\title{
2013/31
}

\section{Contractually stable alliances}

Ana Mauleon, Jose Sempere-Monerris and Vincent Vannetelbosch

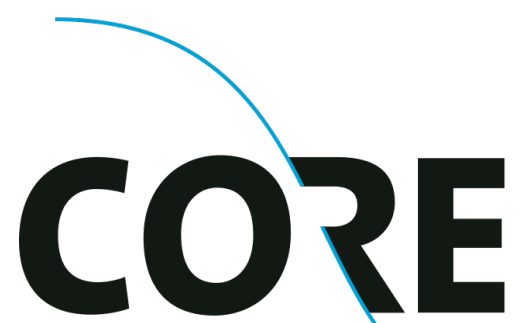

\section{DISCUSSION PAPER}

Center for Operations Research and Econometrics

Voie du Roman Pays, 34 B-1348 Louvain-la-Neuve Belgium http://www.uclouvain.be/core 


\title{
CORE DISCUSSION PAPER
}

2013/31

\section{Contractually stable alliances}

\section{Ana MAULEON ${ }^{1}$, Jose SEMPERE-MONERRIS ${ }^{2}$ and Vincent VANNETELBOSCH ${ }^{3}$}

\author{
May 2013
}

\begin{abstract}
We analyze how different rules for exiting an alliance (simple majority, unanimity or unanimity with side payments) will affect the formation of strategic alliances. We find that no alliance structure is contractually stable under the simple majority rule. Once unanimous consent is required, asymmetric alliance structures consisting of two alliances are contractually stable. In addition, the grand alliance which is the efficient structure is stable. Allowing for side payments to compensate former partners improves efficiency. Finally, we show that different rules of exit may coexist in different alliances in the long run.
\end{abstract}

Keywords: strategic alliances, coalition formation, contractual stability, exit rules.

JEL Classification: C70, L13

\footnotetext{
${ }^{1}$ CEREC, Saint-Louis University, B-1000 Brussels, Belgium; Université catholique de Louvain, CORE, B-1348 Louvain-la-Neuve, Belgium. E-mail: mauleon@fusl.ac.be. This author is also member of ECORE, the association between CORE and ECARES.

2 Department of Economic Analysis and ERI-CES, University of Valencia, E-46002 Valencia, Spain; Université catholique de Louvain, CORE, B-1348 Louvain-la-Neuve, Belgium. E-mail: jose.j.sempere@uv.es.

${ }^{3}$ CEREC, Saint-Louis University, B-1000 Brussels, Belgium; Université catholique de Louvain, CORE, B-1348 Louvain-la-Neuve, Belgium. E-mail: Vincent.vannetelbosch@uclouvain.be. This author is also member of ECORE, the association between CORE and ECARES.
} 


\section{Introduction}

A common practice for firms is to pool their expertise in partnerships such as joint ventures and strategic alliances. ${ }^{1}$ Strategic alliances refer to agreements characterized by the commitment of two or more firms to reach a common goal entailing the pooling of their ressources and activities. The formation of an alliance usually creates negative externalities for nonmembers.

We analyze how different rules for exiting an alliance will affect the formation of strategic alliances. Alliances agreements contain mechanisms to regulate exit. Three rules of exit are commonly used in alliances: (i) exit without breach via a deadlock implemented by the contractual board where only unanimous decisions are taken (a unanimity decision rule), ${ }^{2}$ (ii) exit via breach of the agreement subject to damages (a unanimity decision rule with side payments), (iii) exit at the will of the larger party subject to forewarning (a simple majority decision rule). ${ }^{3}$

We adopt the concept of contractual stability to predict the alliances that are going to emerge at equilibrium. A new partner enters an alliance only if she wishes to come in, her new partners wish to accept her, and she obtains the consent from her former partners to withdraw if she was before member of another alliance. Under the unanimity rule, she needs the consent of all members of her initial alliance. Under the simple majority rule, she needs the consent of at least half of the members of her initial alliance. Under the unanimity rule with side payments, she still needs the unanimous consent of her former partners but she can now make side payments to her former partners in order to reach their approval. Side payments can only be made to members of the initial alliance she wants to leave.

\footnotetext{
${ }^{1}$ Hagedoorn (2002) has reported that in 2000 there were 199 strategic alliances in the biotechnology industry out of 575 strategic alliances counted overall, making biotechnology the first industry in the ranking followed by the information technology (184 alliances) and automotive (53 alliances).

${ }^{2}$ The contractual board is assigned the task of monitoring the alliance activities and shaping ongoing developments. The contractual board is comprised of representatives of each side, usually in equal numbers, but the absolute numbers are not so important, since unanimity is the norm. Given that alliances usually do not provide for easy dissolution, the deadlocks are dealt with according to the terms of the contracts, which ordinarily include a dispute resolution mechanism. See Smith (2005).

${ }^{3}$ Forewarning is usually required for an alliance agreement to be terminable at the will of the larger party. For instance, the Exclusive License and Collaboration Agreement between MedImmune Inc. and Critical Therapeutics Inc. (July 30, 2003) provided that MedImmune had the right to terminate on six months notice. See Smith (2005).
} 
We investigate in Bloch's (1995) model of associations of firms whether requiring the consent of former partners may help to sustain the emergence of more efficient alliances in the long run. We find that there is no contractually stable alliance structure under the simple majority decision rule when the industry consists of more than seven firms. Hence, no alliance structure can be stable without requiring any consent of partners to exit. However, any asymmetric alliance structure consisting of two alliances becomes contractually stable once the unanimity decision rule is adopted. Requiring the consent of all partners to exit reverts to give each partner a veto power to any change made to the alliance. As a consequence, from any asymmetric alliance structure consisting of two alliances, we have that (i) any deviation where an alliance is divided in two or more alliances is now blocked, (ii) any deviation to the grand alliance is blocked, and (iii) any deviation where some members of the smallest alliance leave their alliance to join the largest one is now blocked. Moreover, the grand alliance which is the efficient structure also becomes stable. If we allow for side payments only among former partners in addition to the unanimity rule, then some less efficient structures that were stable without side payments are no more stable. Hence, allowing for side payments and requiring unanimity to exit helps to improve efficiency. The grand alliance remains contractually stable. Finally, we show that different rules of exit may coexist in different alliances at equilibrium. For instance, the asymmetric alliance structure where half-plus-one of the total number of firms are in one alliance and all other firms are in a second alliance is contractually stable when simple majority is in effect in the first alliance while unanimity is in effect in the second alliance.

Joining an alliance requires the unanimous consent of all current members of the alliance. Obviously, a different rule for joining an alliance could lead to different predictions about stable alliance structures. In the open membership game, all firms simultaneously announce a message and alliances are then formed by all firms who have announced the same message. In fact, any firm can form an alliance with another firm simply by announcing the same message. Yi (1997) has shown that the only Nash equilibrium of the open membership game is the grand alliance. ${ }^{4}$

\footnotetext{
${ }^{4}$ Belleflamme (2000) has studied games of coalition formation with open membership where firms form associations or alliances in order to decrease their costs before competing on the market. Once firms are asymmetric, the grand alliance may not be a Nash equilibrium outcome of the game. See also Yi and Shin (2000).
} 
However, there is no strong Nash equilibrium of the open membership game. Bloch (1995) has proposed a sequential game for forming associations of firms. One firm proposes an alliance. All the prospective members of the alliance respond in turn to the offer. If all the firms accept to join the alliance, the proposed alliance is formed and all members benefit from the reduction in marginal cost. If one of the firms does not accept to join the alliance, the proposed alliance is not formed and the firm that did not accept becomes the firm that makes a proposal in the next period. Bloch has shown that in equilibrium, firms form two asymmetric alliances, with the largest one comprising roughly three-quarters of industry members. ${ }^{5}$

The paper is organized as follows. In Section 2 we set up the model. In Section 3 we introduce the notion of contractual stability and we provide results that are independent of the rule for consent. In Section 4 we show that there is no alliance structure that is stable under the simple majority decision rule. In Section 5 we characterize the stable alliance structures under the unanimity decision rule. In Section 6 we introduce side payments. In Section 7 we allow different alliances to use different rules for consent. In Section 8 we conclude.

\section{Strategic Alliances of Firms}

Cooperation among competing firms is increasingly common on oligopolistic markets. More and more often, competing firms agree to share information, build common facilities or launch common research programmes in order to decrease their production costs. Bloch (1995) proposed a simple model to analyze the formation of alliances of firms where the benefits from cooperation increase linearly in the size of the alliance.

Consider a market with $n$ symmetric firms indexed by $i=1,2, \ldots, n$, where $n \geq 4$. The interactions among firms are modelled as a two-stage game. In stage one, alliances are formed. In stage two, given the alliance structure, firms compete on the market. Once alliances are formed, firms behave as competitors on the market and maximize individual profits. Demand is linear and given by $p=\alpha-\sum_{i=1}^{n} q_{i}$, where $\alpha$ measures the absolute size of the market. Firms have a constant marginal cost of production, which is decreasing in the size of the alliance they belong to.

\footnotetext{
${ }^{5}$ Espinosa and Macho-Stadler (2003) have analyzed the formation of associations of firms when effort to reduce costs is not verifiable.
} 
Formally, the cost of a firm $i$ in an alliance $A$ of size $a$ is given by $c_{i}=\lambda-\mu a$. The parameters $\alpha, \lambda$ and $\mu$ are chosen in such a way that, for any alliance structure, all firms are active in a Cournot equilibrium. Once alliances are formed on the market, firms select non-cooperatively the quantities they offer on the market. Let $N=\{1,2, \ldots, n\}$ be the set of firms. An alliance structure $S=\left\{A_{1}, A_{2}, \ldots, A_{m}\right\}$ is a partition of the set of firms such that $A_{i} \cap A_{j}=\emptyset$ for $i \neq j$ and $\bigcup_{i=1}^{m} A_{i}=N$. Let $s$ be the cardinality of $S$ (i.e. the number of alliances in $S$ ). An alliance structure $A$ is symmetric if and only if $a_{i}=a_{j}$ for all $A_{i}, A_{j} \in S$. Let $S^{*}=\{N\}$ be the grand alliance.

For any given alliance structure $S=\left\{A_{1}, A_{2}, \ldots, A_{m}\right\}$, one can easily show that there exists a unique Cournot equilibrium on the market, and that each firm's profit $\Pi_{i}(S)$ is a monotonically increasing function of the following valuation,

$$
V_{i}(S)=\alpha-\lambda+\mu(n+1) a(i)-\mu \sum_{j=1}^{m}\left(a_{j}\right)^{2},
$$

where $a(i)$ denotes the size of the alliance firm $i$ belongs to. In fact, $V_{i}(S)=$ $(n+1) \sqrt{\Pi_{i}(S)}$.

\section{Contractual Stability}

A simple way to analyze the alliances that one might expect to emerge in the long run is to examine a sort of equilibrium requirement that no group of firms benefits from altering the alliance structure. What about possible deviations? An alliance structure $S^{\prime}$ is obtainable from $S$ via $A, A \subseteq N$, if (i) $\left\{A_{i}^{\prime} \in S^{\prime} \mid A_{i}^{\prime} \subseteq N \backslash A\right\}=$ $\left\{A_{i} \backslash A \mid A_{i} \in S, A_{i} \backslash A \neq \emptyset\right\}$ and (ii) $\exists\left\{A_{1}^{\prime}, \ldots, A_{k}^{\prime}\right\} \subseteq S^{\prime}$ such that $\bigcup_{j=1}^{k} A_{j}^{\prime}=A$. Condition (i) means that if the firms in $A$ leave their respective alliance(s) in $S$, the non-deviating firms do not move. Condition (ii) allows the deviating firms in $A$ to form one or several alliances in the new alliance structure $S^{\prime}$. Non-deviating firms do not belong to those new alliances.

Once identified all possible deviations from an existing alliance structure, different stability concepts could be studied. We adopt the concept of contractual stability to predict the alliances that are going to emerge at equilibrium. As in Drèze and Greenberg (1980), we assume that alliances are contracts binding all members and that modifying an alliance requires the consent of the members of the alliance. That is, a new partner will enter an alliance only if she wishes to come 
in, her new partners wish to accept her, and she obtains from her former partners permission to withdraw (only if she was before member of another alliance).

We analyze two different decision rules for consent: the simple majority decision rule and the unanimity decision rule. Both rules reflect rules of exit used in alliances: exit at the will of the larger party subject to forewarning and exit without breach via a deadlock implemented by the contractual board where only unanimous decisions are taken.

Definition 1. An alliance structure $S$ is contractually stable under the unanimity decision rule if for any $A \subseteq N, S^{\prime}$ obtainable from $S$ via $A$ and $i \in A$ such that $V_{i}\left(S^{\prime}\right)>V_{i}(S)$, there exists $k \in A(j)$ with $A(j) \in S$ and $j \in A$ such that $V_{k}\left(S^{\prime}\right) \leq$ $V_{k}(S)$.

Under the unanimity decision rule, the move from an alliance structure $S$ to any obtainable alliance structure $S^{\prime}$ needs the consent of every deviating firm and the consent of every member of the initial alliances of the deviating firms. Then, an alliance structure is contractually stable under the unanimity decision rule if any deviating firm or any member of the former alliances of the deviating firms is not better off from the deviation to any obtainable alliance structure $S^{\prime}{ }^{6}$

Definition 2. An alliance structure $S$ is contractually stable under the simple majority decision rule if for any $A \subseteq N, S^{\prime}$ obtainable from $S$ via $A$ and $i \in A$ such that $V_{i}\left(S^{\prime}\right)>V_{i}(S)$, there exists

(i) $l \in A$ such that $V_{l}\left(S^{\prime}\right) \leq V_{l}(S)$, or

(ii) $\widehat{A} \subseteq A(j)$ with $A(j) \in S$ and $j \in A$ such that $V_{k}\left(S^{\prime}\right) \leq V_{k}(S)$ for all $k \in \widehat{A}$ and $\widehat{a} \geq a(j) / 2$.

Under the simple majority decision rule, the move from an alliance structure $S$ to any obtainable alliance structure $S^{\prime}$ needs the consent of every deviating firm and the consent of more than half members of each initial alliance of the deviating firms. Then, an alliance structure $S$ is contractually stable under the simple majority

\footnotetext{
${ }^{6}$ Firms are not farsighted in the sense that they do not forecast how others might react to their actions. For instance, Konishi and Ray (2003) or Herings, Mauleon and Vannetelbosch (2010) have developed notions to predict which coalitions or groups are likely to be formed among farsighted agents.
} 
decision rule if any deviating firm or at least half members of some former alliance of the deviating firms are not better off from the deviation to any obtainable alliance structure $S^{\prime}$.

Obviously, an alliance structure that is contractually stable under the simple majority decision rule is contractually stable under the unanimity decision rule. In fact each decision rule requires the consent of partners above some proportion for a deviation not to be blocked. Let $q$ denote the proportion of partners whose consent is needed for a deviation not to be blocked, $0 \leq q \leq 1$. For instance, the simple majority decision rule reverts to a proportion $q>1 / 2$ while the unanimity decision rule reverts to a proportion $q=1$. The relationship between contractual stability under any decision rule embodied by a proportion $q$ is obvious: a proportion $q^{\prime}<q$ refines stability. That is, the set of contractually stable alliance structures under $q^{\prime}$ is (weakly) included in the set of contractually stable alliance structures under $q$. Indeed, the probability to block a deviation is greater the higher the proportion $q$. When the proportion approaches zero $(q \rightarrow 0)$, membership has no matter in terms of consent and the concept of contractual stability reverts to Hart and Kurz (1983) notion of $\Delta$-stability.

Definition 3. An alliance structure $S$ is $\Delta$-stable if for any $A \subseteq N, S^{\prime}$ obtainable from $S$ via $A$ and $i \in A$ such that $V_{i}\left(S^{\prime}\right)>V_{i}(S)$, there is $j \in A$ such that $V_{j}\left(S^{\prime}\right) \leq V_{j}(S)$

We first provide some general results about stable alliance structures independently of the decision rule. Lemma 1 tells us that any two alliances have always incentives to merge if both alliance sizes are smaller than $(n+1) / 2$.

Lemma 1. $V_{i}\left(S \backslash\left\{A_{1}, A_{2}\right\} \cup\left\{A_{1} \cup A_{2}\right\}\right)>V_{i}(S)$ for all $i \in A_{1} \cup A_{2}$ if $a_{1}<(n+1) / 2$ and $a_{2}<(n+1) / 2$.

Proof. Consider the incentives for the members of an alliance $A_{1}$ to merge with an alliance $A_{2}$ when no other deviation occurs in the alliance structure. This is given by $V_{i}\left(S \backslash\left\{A_{1}, A_{2}\right\} \cup\left\{A_{1} \cup A_{2}\right\}\right)-V_{i}(S)$, where $S \backslash\left\{A_{1}, A_{2}\right\} \cup\left\{A_{1} \cup A_{2}\right\}$ is the alliance structure formed by merging $A_{1}$ and $A_{2}$ in $S$ and $i$ is any member of $A_{1}$. We have $V_{i}\left(S \backslash\left\{A_{1}, A_{2}\right\} \cup\left\{A_{1} \cup A_{2}\right\}\right)-V_{i}(S)=\left[\mu\left(a_{1}+a_{2}\right)-\mu a_{1}\right](n+1)-$ $\left[\mu\left(a_{1}+a_{2}\right)^{2}-\mu\left(a_{1}\right)^{2}-\mu\left(a_{2}\right)^{2}\right]=\mu a_{2}\left(n+1-2 a_{1}\right)$. So, members of $A_{1}$ have an incentive to merge with $A_{2}$ as long as the size of $A_{1}$, i.e. $a_{1}$, is smaller than $(n+$ 
1) $/ 2$, regardless of the size of $A_{2}$ and of the alliances formed by other firms on the market.

Lemma 1 implies that alliance structures consisting of more than two alliances cannot be contractually stable whatever the decision rule for consent since there always exists two alliances having a size smaller than $(n+1) / 2$.

Lemma 2. Any alliance structure $S$ such that $s>2$ is never contractually stable whatever the decision rule for consent.

Proof. Take any alliance structure $S$ such that $s>2$. Then, there exists at least two alliances $A_{1} \in S$ and $A_{2} \in S$ such that $a_{1}<(n+1) / 2$ and $a_{2}<(n+1) / 2$. From Lemma 1 we have that all members of $A_{1}$ and $A_{2}$ have incentives to merge; and this merger does not request the consent of any other firm than those involved in the merger.

Lemma 1 also implies that any symmetric alliance structure consisting of two alliances cannot be contractually stable since both alliances have a size smaller than $(n+1) / 2$.

Lemma 3. The symmetric alliance structure $S$ such that $s=2$ is never contractually stable whatever the decision rule for consent.

Proof. Take the symmetric alliance structure $S=\left\{A_{1}, A_{2}\right\}$ where $a_{1}=a_{2}=n / 2$. Thus, $a_{1}=a_{2}<(n+1) / 2$, and from Lemma 1 , we have that all members of $A_{1}$ and $A_{2}$ have incentives to merge; and this merger does not request the consent of any other firm than those involved in the merger.

\section{Simple Majority Decision Rule}

We now analyze the stability of alliances when the exit of an alliance requires the consent of a majority of the members of the alliance. We already know that the only candidates for being stable are asymmetric alliance structures consisting of two alliances and the grand alliance structure.

First, we show that asymmetric alliance structures consisting of two alliances cannot be contractually stable under the simple majority decision rule. Take any asymmetric alliance structure $S=\{A, N \backslash A\}$. If the size of the largest alliance in $S=\{A, N \backslash A\}$, say $A$, is small (i.e. $n / 2<a \leq(2 n-1) / 3$ ), then there always exists 
a profitable deviation from $S$ to $S^{\prime}=\{A \cup B,(N \backslash A) \backslash B\}$ where a majority of firms in $N \backslash A$ (i.e. $2 b>n-a$ ) leaves their partners in $N \backslash A$ to join the alliance $A$. If the size of the largest alliance in $S=\{A, N \backslash A\}$ is large (i.e. $(2 n-1) / 3<a \leq n-1)$, then there always exists a profitable deviation from $S=\{A, N \backslash A\}$ to $S^{\prime \prime}=\left\{A^{\prime}, B, N \backslash A\right\}$ where a majority of firms in $A$ (i.e. $a>2 b$ ) drops $b$ former partners.

Lemma 4. Any asymmetric alliance structure $S$ such that $s=2$ is never contractually stable under the simple majority decision rule for $n$ big enough $(n \geq 8)$.

Proof. Take any asymmetric alliance structure consisting of two alliances, $S=$ $\{A, N \backslash A\}$, where $n-1 \geq a>n / 2$. For all $i \in A$, we have $V_{i}(\{A, N \backslash A\})=\alpha-\lambda+$ $\mu\left[(n+1) a-(a)^{2}-(n-a)^{2}\right]=\alpha-\lambda+\mu\left[(3 n+1) a-2(a)^{2}-n^{2}\right]$. For all $j \in N \backslash A$, we have $V_{j}(\{A, N \backslash A\})=\alpha-\lambda+\mu\left[(n+1)(n-a)-(a)^{2}-(n-a)^{2}\right]=\alpha-\lambda+$ $\mu\left[(n-1) a-2(a)^{2}+n\right]$. Since $a>n / 2$, we have $V_{i}(\{A, N \backslash A\})>V_{j}(\{A, N \backslash A\})$, $i \in A$ and $j \in N \backslash A$.

[Case 1.] Suppose that $n / 2<a \leq(2 n-1) / 3$.

We will show that there always exists a group of firms $B$ belonging to $N \backslash A$ $(B \subset N \backslash A)$ who has incentives to leave $N \backslash A$ to join the alliance $A$. That is, we consider the deviation from $S=\{A, N \backslash A\}$ to $S^{\prime}=\{A \cup B,(N \backslash A) \backslash B\}$. We will show that all members of $A$ and $B$ prefer $S^{\prime}$ to $S$ and that this deviation is not blocked by former partners of $B$ in $N \backslash A$ according to the simple majority rule. For all $i \in A \cup B$, we have $V_{i}(\{A \cup B,(N \backslash A) \backslash B\})=\alpha-\lambda+\mu\left[(n+1) a+(n+1) b-(a+b)^{2}-(n-a-b)^{2}\right]=$ $\alpha-\lambda+\mu\left[(n+1) a-(a)^{2}-(n-a)^{2}+b(3 n+1-4 a-2 b)\right]$. For all $j \in(N \backslash A) \backslash B$, we have $V_{j}(\{A \cup B,(N \backslash A) \backslash B\})=\alpha-\lambda+\mu\left[(n+1)(n-a)-(n+1) b-(a+b)^{2}-(n-a-b)^{2}\right]=$ $\alpha-\lambda+\mu\left[(n+1)(n-a)-(a)^{2}-(n-a)^{2}+b(n-1-4 a-2 b)\right]$.

(a) Members of the alliance $A$ will obtain a higher payoff when $b$ firms join their alliance only if $b<(3 n+1-4 a) / 2=(n-a) / 2+n-(3 a-1) / 2$. Notice that $(3 n+1-4 a) / 2 \geq 1$ if and only if $a \leq(3 n-1) / 4$.

(b) Members of $B$ have incentives to join $A$ if and only if $b(3 n+1-4 a-2 b)>$ $(n+1)(n-2 a)$. Since $a>n / 2$, the right-hand side of the above expression is negative, and therefore, a sufficient condition is $3 n+1-4 a-2 b>0$, which is the same condition for having members in $A$ obtaining a higher payoff when accepting $b$ new members.

(c) Firms belonging to $(N \backslash A) \backslash B$ are worse off in $S^{\prime}$ than in $S$. Thus, members of $B$ need to have a majority in $N \backslash A$ in order to be allowed to leave the alliance 
$N \backslash A$. That is, $b>(n-a) / 2$.

From (a), (b), (c), the deviation from $S$ to $S^{\prime}$ by $A \cup B$ will not be blocked if and only if $(n-a) / 2<b \leq(n-a) / 2+n-(3 a-1) / 2$. This interval is well defined only if $a \leq(2 n-1) / 3 .^{7}$

[Case 2.] Suppose that $(2 n-1) / 3<a$.

We will show that there always exists a group of firms $A^{\prime}$ belonging to $A\left(A^{\prime} \subset\right.$ $A$ ) who has incentives to leave alone $b$ former partners. That is, we consider the deviation from $S=\{A, N \backslash A\}$ to $S^{\prime \prime}=\left\{A^{\prime}, B, N \backslash A\right\}$ where $A^{\prime}=A \backslash B$. Two conditions are required so that this deviation is not blocked.

(a) Members of $A^{\prime}$ who deviate need to have the majority within $A$; that is, $b<a / 2$.

(b) Members of $A^{\prime}$ have to be better off in $S^{\prime \prime}$ than in $S$. For all $i \in A \backslash B$, $V_{i}\left(\left\{A^{\prime}, B, N \backslash A\right\}\right)=\alpha-\lambda+\mu\left[(n+1)(a-b)-(a-b)^{2}-(b)^{2}-(n-a)^{2}\right]=$ $\alpha-\lambda+\mu\left[(n+1) a-(a)^{2}-(n-a)^{2}-b(n+1-2 a+2 b)\right]$. For all $i \in A, V_{i}(\{A, N \backslash A\})=$ $\alpha-\lambda+\mu\left[(n+1) a-(a)^{2}-(n-a)^{2}\right]$. Therefore, members of $A \backslash B$ are better off in $S^{\prime \prime}$ than in $S$ if and only if $a-b>(n+1) / 2$. Thus, the deviation from $S$ to $S^{\prime \prime}$ by $A \backslash B$ will not be blocked if and only if $1 \leq b<\min \{a / 2, a-(n+1) / 2\}$. Since $a-(n+1) / 2>1$ for $n \geq 8$, there always exists a size $b$ such that the deviation is not blocked. ${ }^{8}$

Second, we show that the grand alliance structure cannot be contractually stable under the simple majority decision rule. In fact, there always exists a majority of firms in $N$ (i.e. $2 a>n$ ) who has incentives to leave their partners in $N$ to form a new alliance $A$.

Lemma 5. The grand alliance $S^{*}=\{N\}$ is never contractually stable under the simple majority decision rule (for $n>3$ ).

\footnotetext{
${ }^{7}$ For $a>(3 n-1) / 4$, there is no positive $b$ that will make members of $A$ accepting the deviation from $S$ to $S^{\prime}$. However, when $(2 n-1) / 3<a \leq(3 n-1) / 4$, the $b$ members that are accepted by $A$ are not sufficiently large to be a majority in $N \backslash A$.

${ }^{8}$ For $n=3,\{N\}$ is the unique contractually stable alliance structure under the simple majority decision rule. For $4 \leq n \leq 5$, there is a unique contractually stable alliance structure under the simple majority decision rule: $\{A, N \backslash A\}$ with $a=n-1$. For $n=6$, the unique contractually stable alliance structures under the simple majority decision rule are $\{A, N \backslash A\}$ with $n-2 \leq a \leq n-1$. For $n=7$, the unique contractually stable alliance structures under the simple majority decision rule are $\{A, N \backslash A\}$ with $a=n-2$.
} 
Proof. We will show that, from the grand alliance $\{N\}$, there always exists a group of firms $A$ of $N(A \subset N)$ who has incentives to leave $N$. That is, we consider the deviation from $S^{*}=\{N\}$ to $S^{\prime \prime \prime}=\{A, N \backslash A\}$. We will show that (i) all members of $A$ prefer $S^{\prime \prime \prime}$ to $S^{*}$; (ii) this deviation is not blocked by former partners, that is, members of $N \backslash A$. Take $A$ such that the size of the alliance $A$, i.e. $a$, is the integer closest to $(3 n+1) / 4$. If two integers are equally close to $(3 n+1) / 4$, the alliance size can take on those two values. Two conditions are required so that this deviation is not blocked.

(a) Members of $A$ who deviate need to have the majority within $N$. Since the size of $A$ is the integer closest to $(3 n+1) / 4$, we have that $n / 2<a$.

(b) Members of $A$ have to be better off in $S^{\prime \prime \prime}$ than in $S^{*}$. For all $i \in A, V_{i}(\{N\})=$ $\alpha-\lambda+\mu\left[(n+1)(n)-(n)^{2}\right]$. For all $i \in A, V_{i}(\{A, N \backslash A\})=\alpha-\lambda+\mu[(n+1) a-$ $\left.(a)^{2}-(n-a)^{2}\right]$. Since the size of $A$ is the integer closest to $(3 n+1) / 4$ and $n \geq 4$, we have that $(n+1) a-(a)^{2}-(n-a)^{2}>(n+1)(n)-(n)^{2}$.

Using Lemma 2 to Lemma 5 we conclude that there is no contractually stable alliance structure under the simple majority rule when the size of the industry is not too small.

Proposition 1. There is no contractually stable alliance structure under the simple majority rule for $n \geq 8$.

Since an alliance structure that is $\Delta$-stable under Hart and Kurz (1983) notion of stability is contractually stable under the simple majority decision rule, we have that there is no $\Delta$-stable alliance structure.

Corollary 1. There is no $\Delta$-stable alliance structure for $n \geq 8$.

\section{Unanimity Decision Rule}

We now analyze the stability of alliances when the exit of an alliance requires the consent of all members of the alliance. We show that, once each partner can veto any change made to the alliance, then any asymmetric alliance structure consisting of two alliances becomes contractually stable. Lemma 6 tells us that, from any alliance structure consisting of two or more alliances, any deviation where an alliance is divided in two or more alliances is blocked under the unanimity rule. 
Lemma 6. Take any alliance structure $S \neq S^{*}$. Then, any deviation from $S$ to $S^{\prime}$ where an alliance $A \in S$ is divided into two (or more) alliances is blocked under the unanimity decision rule.

Proof. Take any alliance structure $S \neq S^{*}$. The deviation from $S$ to $S^{\prime}=S \backslash\{A\} \cup$ $\left\{A_{1}, A_{2}\right\}$ with $A_{1} \cup A_{2}=A$ is blocked because (i) at least one of the new alliances $A_{1}$ or $A_{2}$ has a size strictly smaller than $(n+1) / 2$ and so, by Lemma 1 , the members of this alliance are worse off in $S^{\prime}$ than in $S$, and (ii) unanimity of members of $A$ is required.

Lemma 7 tells us that, from any asymmetric alliance structure consisting of two alliances, any deviation to the grand alliance structure is blocked under the unanimity rule.

Lemma 7. Take any asymmetric alliance structure $S$ with $s=2$. Then, any deviation from $S$ to $S^{*}$ is blocked under the unanimity decision rule.

Proof. For all $i \in N$, we have $V_{i}(\{N\})=\alpha-\lambda+\mu\left[(n+1)(n)-(n)^{2}\right]$. Take any asymmetric alliance structure $S=\{A, N \backslash A\}$. Without loss of generality, let $a \geq$ $(n+1) / 2$. For all $i \in A$, we have $V_{i}(\{A, N \backslash A\})=\alpha-\lambda+\mu\left[(n+1) a-(a)^{2}-(n-a)^{2}\right]$. For all $i \in N \backslash A$, we have $V_{i}(\{A, N \backslash A\})=\alpha-\lambda+\mu\left[(n+1)(n-a)-(a)^{2}-(n-a)^{2}\right]$. Comparing those expressions and given that $a \geq(n+1) / 2$, members of $A$ block the deviation from $S=\{A, N \backslash A\}$ to $S^{*}=\{N\}$ because they are not better off in $S^{*}$ (i.e., $V_{i}(\{N\}) \leq V_{i}(\{A, N \backslash A\})$, for all $\left.i \in A\right)$.

Lemma 8 tells us that, from any asymmetric alliance structure consisting of two alliances, any deviation where some members of the smallest alliance leave their alliance to join the largest alliance is blocked under the unanimity rule.

Lemma 8. Take any asymmetric alliance structure $S=\{A, N \backslash A\}$ with $a \leq n-1$. Then, any deviation from $S=\{A, N \backslash A\}$ to $S^{\prime}=\{A \cup B,(N \backslash A) \backslash B\}$ with $B \subset N \backslash A$ is blocked under the unanimity decision rule.

Proof. [Case 1.] Suppose that $(n+1) / 2 \leq a \leq n-1$.

Take any asymmetric alliance structure $S=\{A, N \backslash A\}$ and consider the deviation from $S$ to $S^{\prime}=\{A \cup B,(N \backslash A) \backslash B\}$ with $B \subset N \backslash A$. For all $i \in N \backslash A$, we have $V_{i}(\{A, N \backslash A\})=\alpha-\lambda+\mu\left[(n+1)(n-a)-(a)^{2}-(n-a)^{2}\right]$. For all $i \in(N \backslash A) \backslash B$, we have $V_{i}(\{A \cup B,(N \backslash A) \backslash B\})=\alpha-\lambda+\mu\left[(n+1)(n-a-b)-(a+b)^{2}-(n-a-b)^{2}\right]=$ 
$\alpha-\lambda+\mu\left[(n+1)(n-a)-(a)^{2}-(n-a)^{2}+b(n-1-4 a-2 b)\right]$. Thus, members of $(N \backslash A) \backslash B$ block the deviation from $S=\{A, N \backslash A\}$ to $S^{\prime}=\{A \cup B,(N \backslash A) \backslash B\}$ if and only if $(n-1-4 a) / 2<b$. This condition is always satisfied since $(n+1) / 2 \leq a$.

[Case 2.] Suppose that $a<(n+1) / 2$.

Take any asymmetric alliance structure $S=\{A, N \backslash A\}$ and consider the deviation from $S$ to $S^{\prime}=\{A \cup B,(N \backslash A) \backslash B\}$ with $B \subset N \backslash A$. For all $i \in(N \backslash A) \backslash B$, we have $V_{i}(\{A \cup B,(N \backslash A) \backslash B\})=\alpha-\lambda+\mu\left[(n+1)(n-a)-(a)^{2}-(n-a)^{2}+\right.$ $b(n-1-4 a-2 b)]$, and $V_{i}(\{A, N \backslash A\})=\alpha-\lambda+\mu\left[(n+1)(n-a)-(a)^{2}-(n-a)^{2}\right]$. Thus, each $i \in(N \backslash A) \backslash B$ blocks the deviation if and only if $(n-1-4 a) / 2<b$.

For all $i \in B$, we have $V_{i}(\{A \cup B,(N \backslash A) \backslash B\})=\alpha-\lambda+\mu\left[(n+1)(a+b)-(a+b)^{2}-\right.$ $\left.(n-a-b)^{2}\right]$, and $V_{i}(\{A, N \backslash A\})=\alpha-\lambda+\mu\left[(n+1)(n-a)-(a)^{2}-(n-a)^{2}\right]$. Thus, each $i \in B$ has incentives to deviate if and only if $b(3 n+1-4 a)-2 b^{2}-(n-2 a)(n+1)>0$.

For all $i \in A$, we have $V_{i}(\{A \cup B,(N \backslash A) \backslash B\})=\alpha-\lambda+\mu[(n+1)(a+b)-(a+$ $\left.b)^{2}-(n-a-b)^{2}\right]$, and $V_{i}(\{A, N \backslash A\})=\alpha-\lambda+\mu\left[(n+1) a-(a)^{2}-(n-a)^{2}\right]$. Thus, each $i \in A$ has incentives to accept members of $B$ if and only if $3 n+1-4 a-2 b>0$. Notice that $V_{i}(\{A \cup B,(N \backslash A) \backslash B\})-V_{i}(\{A, N \backslash A\})>0$ for $i \in A$ whenever $V_{i}(\{A \cup B,(N \backslash A) \backslash B\})-V_{i}(\{A, N \backslash A\})>0$ for $i \in B$. Then, we need to find the conditions for $b(3 n+1-4 a)-2 b^{2}-(n-2 a)(n+1)>0$. Since the second derivative with respect to $b$ is negative, $b(3 n+1-4 a)-2 b^{2}-(n-2 a)(n+1)>0$ between the two roots for which $b(3 n+1-4 a)-2 b^{2}-(n-2 a)(n+1)=0$. Solving this equation we find the roots for $b$; that is, $b^{-}=n-2 a$ and $b^{+}=(n+1) / 2$. Comparing the roots we have the following: if $a<(n-1) / 4$, then $b$ should be such that $b \in[(n+1) / 2, n-2 a]$, while if $a>(n-1) / 4$, then $b$ should be such that $b \in[n-2 a,(n+1) / 2]$, in order for $V_{i}(\{A \cup B,(N \backslash A) \backslash B\})-V_{i}(\{A, N \backslash A\})>0$ for $i \in B$.

But then the condition for $i \in(N \backslash A) \backslash B$ to block the deviation from $S$ to $S^{\prime}$ is satisfied. That is, we have that $(n-1-4 a) / 2<b$. Indeed, if $a>(n-1) / 4$, we have that $(n-1-4 a) / 2<0$ and, hence, $(n-1-4 a) / 2<b$. Moreover, if $a<(n-1) / 4$ and $b \in[(n+1) / 2, n-2 a]$, then we have that $b>(n+1) / 2>(n-1-4 a) / 2$.

Using Lemma 6 to Lemma 8 we have that any asymmetric alliance structure consisting of two alliances is contractually stable under the unanimity decision rule since all possible profitable deviations are blocked.

Proposition 2. Any asymmetric alliance structure $S$ such that $s=2$ is contractu- 
ally stable under the unanimity decision rule.

Moreover, once the exit of an alliance requires the consent of all members of the alliance, the grand alliance which is the efficient structure becomes contractually stable.

Proposition 3. The grand alliance $S^{*}=\{N\}$ is always contractually stable under the unanimity decision rule.

Proof. The grand alliance $S^{*}=\{N\}$ is the efficient alliance structure. We have that $n V_{i}(\{N\})>\sum_{j=1}^{m} a_{j} V_{i}(S)$ for any $S=\left\{A_{1}, A_{2}, \ldots, A_{m}\right\}$ such that $S \neq\{N\}$. Under the unanimity decision rule, any deviation from $S^{*}$ to any $S$ requires the approval of all members of $N$. Therefore, any deviation from $S^{*}$ to any $S$ is blocked by at least one member of $N$ who will be worse off in $S$ than in $S^{*}$.

We now compare the outcomes obtained under the notion of contractual stability with those obtained under a sequential game of coalition formation proposed by Bloch (1996). ${ }^{9}$ A fixed protocol is assumed and the sequential game proceeds as follows. Firm 1 proposes the formation of an alliance $A_{1}$ to which she belongs. Each prospective firm answers the proposal in the order fixed by the protocol. If one prospective firm rejects the proposal, then she makes a counter-proposal to which she belongs. If all prospective firms accept, then the alliance $A_{1}$ is formed. All firms in $A_{1}$ withdraw from the game, and the game proceeds among the firms belonging to $N \backslash A_{1}$. This sequential game has an infinite horizon, but the firms do not discount the future. The firms who do not reach an agreement in finite time receive a payoff of zero. Once some firms have agreed to form an alliance they are committed to remain in that alliance. Bloch (1995) has shown that the inefficient alliance structure $S=\left\{A^{*}, N \backslash A^{*}\right\}$ where of a dominant alliance grouping around three quarters (i.e. $a^{*}$ is the integer closest to $\left.(3 n+1) / 4\right)$ of the industry forms and the remaining firms form a smaller alliance is the unique symmetric stationary perfect equilibrium outcome of the sequential game. Contractual stability under the unanimity decision rule not only sustains this inefficient alliance structure but also stabilizes the efficient grand alliance.

\footnotetext{
${ }^{9}$ See also Ray and Vohra (1999).
} 


\section{Unanimity Decision Rule with Side Payments}

Beside exit at the will of the larger party subject to forewarning (simple majority rule) and exit without breach via a deadlock implemented by the contractual board where only unanimous decisions are taken (unanimity rule), a third rule is commonly used in alliances to govern exit: exit via breach of the agreement subject to damages. This third rule can be modelled by allowing for side payments among partners in addition to the unanimity decision rule.

Definition 4. An alliance structure $S$ is contractually stable under side payments and the unanimity decision rule if for any $A \subseteq N, S^{\prime}$ obtainable from $S$ via $A$ and $i \in A$ such that $V_{i}\left(S^{\prime}\right)>V_{i}(S)$, there is $j \in A$ such that either $V_{j}\left(S^{\prime}\right) \leq V_{j}(S)$ or

$$
\sum_{k \in A(j) \in S} V_{k}\left(S^{\prime}\right) \leq \sum_{k \in A(j) \in S} V_{k}(S)
$$

When a group of firms deviate by leaving some alliance, they can now compensate their former partners to obtain their consent. Obviously, an alliance structure that is contractually stable under the unanimity decision rule with side payments is contractually stable under the unanimity decision rule without side payments.

Proposition 4. Allowing for side payments among partners, the contractually stable alliance structures under the unanimity decision rule are

(i) any asymmetric alliance structure $S=\{A, N \backslash A\}$ with $(3 n-1) / 4<a \leq n-1$.

(ii) the grand alliance structure $S^{*}=\{N\}$.

Proof. First, we show that the $b$ members of $B$ can compensate the $n-a-b$ members of $(N \backslash A) \backslash B$ when they deviate jointly with members of $A$ from $S=$ $\{A, N \backslash A\}$ to $S^{\prime}=\{A \cup B,(N \backslash A) \backslash B\}$. Indeed, we have $\sum_{l \in N \backslash A, N \backslash A \in S} V_{l}\left(S^{\prime}\right)>$ $\sum_{l \in N \backslash A, N \backslash A \in S} V_{l}(S)$ where $\sum_{l \in N \backslash A, N \backslash A \in S} V_{l}\left(S^{\prime}\right)=(n-a)(\alpha-\lambda)+\mu b[(n+1)(a+$ $\left.b)-(a+b)^{2}-(n-a-b)^{2}\right]+\mu(n-a-b)\left[(n+1)(n-a-b)-(a+b)^{2}-(n-a-b)^{2}\right]$ and $\sum_{l \in N \backslash A, N \backslash A \in S} V_{l}(S)=(n-a)(\alpha-\lambda)+\mu(n-a)\left[(n+1)(n-a)-(a)^{2}-(n-a)^{2}\right]$. Then, $\sum_{l \in N \backslash A, N \backslash A \in S} V_{l}\left(S^{\prime}\right)>\sum_{l \in N \backslash A, N \backslash A \in S} V_{l}(S)$ if and only if $b>[n(a+2)-$ $a(3+4 a)] /[2(a+1)]$. This condition is always satisfied since $1>[n(a+2)-a(3+$ $4 a)] /[2(a+1)]$ for $a \geq n / 2$. Remember from the proof of Lemma 4 that only for $a \leq(3 n-1) / 4$ there exists $b \geq 1$ that makes members of $A$ accepting the deviation from $S$ to $S^{\prime}$. 
Second, we show that the $a-b$ members of $A$ who deviate cannot compensate the other $b$ members of $A$ when they deviate from $S=\{A, N \backslash A\}$ to $S^{\prime}=\{A \backslash B, B, N \backslash$ $A\}$. Indeed, we have $\sum_{k \in A \in S} V_{k}\left(S^{\prime}\right) \leq \sum_{k \in A \in S} V_{k}(S)$ where $\sum_{k \in A \in S} V_{k}(S)=a(\alpha-$ $\lambda)+\mu a\left[(n+1) a-(a)^{2}-(n-a)^{2}\right]$ and $\sum_{k \in A \in S} V_{k}\left(S^{\prime}\right)=a(\alpha-\lambda)+\mu(a-b)[(n+$ 1) $\left.(a-b)-(a-b)^{2}-(b)^{2}-(n-a)^{2}\right]+\mu b\left[(n+1) b-(a-b)^{2}-(b)^{2}-(n-a)^{2}\right]$. Then, $\sum_{k \in A \in S} V_{k}\left(S^{\prime}\right) \leq \sum_{k \in A \in S} V_{k}(S)$ if and only if $(n+1)-a>0$, a condition which is always satisfied.

Once we allow for side payments among partners when breaking up an alliance, some asymmetric alliance structures consisting of two alliances are no more contractually stable under the unanimity rule. When the largest alliance in $S=\{A, N \backslash A\}$ (i.e. $A)$ is not too large (i.e. $a \leq(3 n-1) / 4)$ the deviation from $S$ to $S^{\prime}=$ $\{A \cup B,(N \backslash A) \backslash B\}$ where $b$ firms leave the alliance $N \backslash A$ to join the alliance $A$ to form a new alliance $A \cup B$ is not blocked since the net gains made by the $b$ firms in $S^{\prime}$ are large enough to make side payments to the members of $(N \backslash A) \backslash B$ for getting their consent in breaking up the alliance $N \backslash A$. Notice that $a \leq(3 n-1) / 4$ is the condition that guarantees the profitability for members of $A$ of welcoming $b \geq 1$ new partners. However, once the largest alliance is large enough (i.e. $(3 n-1) / 4<a)$, any asymmetric alliance structure $S=\{A, N \backslash A\}$ is still contractually stable even if it is possible to compensate former partners. Indeed, some members of $A$ would like to drop some partners but they cannot compensate those partners to reach their consent. Finally, the grand alliance structure remains contractually stable because it is efficient and all firms belong to the same alliance (hence, each firm can veto any change to the alliance structure).

We now illustrate our main results by means of an example with eight firms. In Table 1 we give the payoffs for $\alpha-\lambda=42$ and $\mu=1$. We make a slight abuse of notation. For instance, $\{5,2,1\}$ should not be interpreted as a single alliance structure but as the alliance structures, composed by three alliances of size 5,2 and 1 , that can be formed by eight firms. The alliance structure $\{5,3\}$ is no more contractually stable once side payments are allowed since the deviation to $\{7,1\}$ is not blocked because the two firms that are changing of alliance can compensate their former partner. Notice that $\{5,3\}$ is the less efficient structure among the contractually stable ones under the unanimity rule without side payments. Hence, allowing for side payments and requiring unanimity helps to improve efficiency. In addition, the efficient structure $\{8\}$ is still stable but is never the outcome of Bloch's 
sequential game of coalition formation that selects $\{6,2\} .{ }^{10}$

\begin{tabular}{lcccccc}
\hline \hline Coalitions: & $\{8\}$ & $\{7,1\}$ & $\{6,2\}$ & $\{6,1,1\}$ & $\{5,2,1\}$ & $\{5,3\}$ \\
Payoffs: & $(50)$ & $(55,1)$ & $(56,20)$ & $(58,13,13)$ & $(57,30,21)$ & $(53,35)$ \\
Stability: & & & & & & \\
1. Unanimity & yes & yes & yes & no & no & yes \\
2. Side payments & yes & yes & yes & no & no & no \\
\hline \hline
\end{tabular}

Table 1: The 8-firm case with $\alpha-\lambda=42, \mu=1$, and all payoffs in $1 / 9$-th's.

\section{Heterogeneous Decision Rules}

We now consider the case where alliances may have different rules of exit: either the simple majority decision rule $\left(q_{m}\right)$ or the unanimity decision rule $\left(q_{u}\right)$.

We denote by $S=\left\{\left(A, q_{u}\right),\left(N \backslash A, q_{m}\right)\right\}$ an alliance structure where, in alliance $A$, the rule of exit is the unanimity decision rule while, in alliance $N \backslash A$, the rule of exit is the simple majority rule. Which alliance structures are now contractually stable?

Obviously, any asymmetric alliance structure $S=\left\{\left(A, q_{u}\right),\left(N \backslash A, q_{u}\right)\right\}$ is still contractually stable and the grand alliance structure $S^{*}=\left\{\left(N, q_{u}\right)\right\}$ is contractually stable too.

Proposition 5. The contractually stable alliance structures when alliances may have different rules of exit are

(i) any asymmetric alliance structure $S=\left\{\left(A, q_{u}\right),\left(N \backslash A, q_{m}\right)\right\}$ with $(2 n-1) / 3<$ $a \leq n-1$.

(ii) any asymmetric alliance structure $S=\left\{\left(A, q_{m}\right),\left(N \backslash A, q_{u}\right)\right\}$ with $n / 2<a \leq$ $(n+3) / 2$.

\footnotetext{
${ }^{10}$ For the equilibrium binding agreements game of Ray and Vohra (1997), the most concentrated stable alliance structure in our model is $\{(n+3) / 2,(n-3) / 2\}$ (see Yi, 1997). It reverts to $\{5,3\}$ in our example with eight firms. Moreover, none of the contractually stable alliances with side payments are stable in the equilibrium binding agreements game.
} 
Proof. From the above analysis we have that the alliance structures with different rules that could be contractually stable are any asymmetric alliance structure $S=$ $\left\{\left(A, q_{u}\right),\left(N \backslash A, q_{m}\right)\right\}$ or $S=\left\{\left(A, q_{m}\right),\left(N \backslash A, q_{u}\right)\right\}$.

First, we consider any asymmetric alliance structure $S=\left\{\left(A, q_{u}\right),\left(N \backslash A, q_{m}\right)\right\}$. Suppose that $n / 2<a \leq(2 n-1) / 3$. We know from the proof of Lemma 4 that there always exists a group of firms $B$ belonging to $N \backslash A(B \subset N \backslash A)$ who has incentives to leave $N \backslash A$ to join the alliance $A$ such that (i) all members of $A$ and $B$ prefer $S^{\prime}=\left\{\left(A \cup B, q_{u}\right),\left((N \backslash A) \backslash B, q_{m}\right)\right\}$ to $S=\left\{\left(A, q_{u}\right),\left(N \backslash A, q_{m}\right)\right\}$ and (ii) former partners of $B$ in $N \backslash A$ do not block this deviation according to the simple majority rule. Suppose now that $(2 n-1) / 3<a$. Even though there always exists a group of firms $A^{\prime}$ belonging to $A\left(A^{\prime} \subset A\right)$ who has incentives to leave alone $b$ former partners, we have from Lemma 6 that the deviation from $S=\left\{\left(A, q_{u}\right),\left(N \backslash A, q_{m}\right)\right\}$ to $S^{\prime \prime}=\left\{\left(A^{\prime}, q_{u}\right),\left(B, q_{u}\right),\left(N \backslash A, q_{m}\right)\right\}$ where $A^{\prime}=A \backslash B$ is blocked because of the unanimity decision rule in $A$.

Second, we consider any asymmetric alliance structure $S=\left\{\left(A, q_{m}\right),\left(N \backslash A, q_{u}\right)\right\}$. Suppose that $(2 n-1) / 3<a$. From Lemma 4 we have that there always exists a group of firms $A^{\prime}$ belonging to $A\left(A^{\prime} \subset A\right)$ who has incentives to leave alone $b$ former partners and that this deviation from $S=\left\{\left(A, q_{m}\right),\left(N \backslash A, q_{u}\right)\right\}$ to $S^{\prime \prime}=$ $\left\{\left(A^{\prime}, q_{m}\right),\left(B, q_{m}\right),\left(N \backslash A, q_{u}\right)\right\}$ where $A^{\prime}=A \backslash B$ is not blocked because of the simple majority decision rule in $A$. Suppose now that $n / 2<a \leq(2 n-1) / 3$. We know from the proof of Lemma 4 that there always exists a group of firms $B$ belonging to $N \backslash A(B \subset N \backslash A)$ who has incentives to leave $N \backslash A$ to join the alliance $A$ such that all members of $A$ and $B$ prefer $S^{\prime}=\left\{\left(A \cup B, q_{m}\right),\left((N \backslash A) \backslash B, q_{u}\right)\right\}$ to $S=\left\{\left(A, q_{m}\right),\left(N \backslash A, q_{u}\right)\right\}$. However, former partners of $B$ in $N \backslash A$ now block this deviation according to the unanimity rule in $N \backslash A$. For each $i \in(N \backslash A) \backslash B, V_{i}(\{(A \cup$ $\left.\left.\left.B, q_{m}\right),\left((N \backslash A) \backslash B, q_{u}\right)\right\}\right)=\alpha-\lambda+\mu\left[(n+1)(n-a-b)-(a+b)^{2}-(n-a-b)^{2}\right]$ and for each $i \in(N \backslash A), V_{i}\left(\left\{\left(A, q_{m}\right),\left(N \backslash A, q_{u}\right)\right\}\right)=\alpha-\lambda+\mu\left[(n+1)(n-a)-(a)^{2}-(n-a)^{2}\right]$. Hence, each $i \in(N \backslash A) \backslash B$ blocks the deviation if and only if $(n-1-4 a) / 2<b$. This condition is always satisfied since $n / 2<a$. Finally, we need to check that there are no incentives for $A^{\prime} \subset A$ to move from $S=\left\{\left(A, q_{m}\right),\left(N \backslash A, q_{u}\right)\right\}$ to $S^{\prime \prime}=\left\{\left(A^{\prime}, q_{m}\right),\left(B, q_{m}\right),\left(N \backslash A, q_{u}\right)\right\}$ where $A^{\prime}=A \backslash B$. This deviation is profitable for members of $A^{\prime}$ if and only if $1 \leq b<a-(n+1) / 2$. Thus, for $(n+3) / 2<$ $a \leq(2 n-1) / 3$ this deviation is not blocked and $S=\left\{\left(A, q_{m}\right),\left(N \backslash A, q_{u}\right)\right\}$ is not contractually stable; but for $n / 2<a \leq(n+3) / 2$ the deviation is blocked and 
$S=\left\{\left(A, q_{m}\right),\left(N \backslash A, q_{u}\right)\right\}$ is contractually stable.

Asymmetric alliance structures $\left\{\left(A, q_{u}\right),\left(N \backslash A, q_{m}\right)\right\}$ where the size of $A$ is not too large and the unanimity rule is in effect in $A$ are not contractually stable since the profitable deviation for a majority of members of $N \backslash A$ to join the alliance $A$ is not blocked. Once the size of $A$ becomes large, there is a profitable deviation for a majority of firms in $A$ to reduce the size of their alliance by excluding some partners, but those targeted partners can veto any change made to the alliance thanks to the unanimity rule in effect in $A$. Hence, any asymmetric alliance structure $S=\left\{\left(A, q_{u}\right),\left(N \backslash A, q_{m}\right)\right\}$ with $(2 n-1) / 3<a \leq n-1$ is contractually stable.

Moreover, any asymmetric alliance structure $\left\{\left(A, q_{m}\right),\left(N \backslash A, q_{u}\right)\right\}$ with $n / 2<$ $a \leq(n+3) / 2$ is contractually stable when simple majority is in effect in the largest alliance while unanimity is in effect in the smallest one. When the size of $A$ becomes larger then the deviation where a majority of $A$ excludes some partners is not blocked. Notice that such asymmetric alliance structures are not stable if simple majority was in effect in both alliances. Then, a majority of firms in $N \backslash A$ would leave $N \backslash A$ to join the alliance $A$ and this deviation would not be blocked by their former partners in $N \backslash A$ because of the simple majority rule.

So, our model is consistent with the observation that different rules of exit in alliances are used in different alliances that are competing in related markets (see Gulati, Sytch and Mehrotra, 2008).

\section{Conclusion}

We have analyze how different rules for exiting an alliance (simple majority, unanimity or unanimity with side payments) affect the formation of strategic alliances. No alliance structure is contractually stable under the simple majority rule. Once unanimous consent is required, asymmetric alliance structures consisting of two alliances are contractually stable. In addition, the grand alliance (which is the efficient structure) is stable. Allowing for side payments to compensate former partners improves efficiency. Finally, we have shown that different rules of exit may coexist in different alliances in the long run

Minehart and Neeman (1999) have analyzed two termination contracts that are widely used in practice (the shotgun rule and price competition) to dissolve partnerships. Under the shotgun rule (also known as the Texas Shootout), one partner 
proposes a price and the other decides whether to buy or sell at that price. Under the price competition, both partners submit bids and the high bidder buys the shares of the low bidder at a price equal to the higher bid. Minehart and Neeman have evaluated the performance of each termination contract to achieve the success of the partnership. They have found that although these contracts do not achieve full efficiency, they both perform well. ${ }^{11}$ While rules governing an alliance are mostly designed to guarantee the success of the alliance, we have shown that rules for exiting an alliance are important to determine the size and the number of alliances that will be formed in the industry.

An interesting extension is to allow for the existence of overlapping alliances. For instance, it may happen that firms A, B and C may decide to form an alliance altogether while firms $\mathrm{A}$ and $\mathrm{D}$ form a partnership. A first step is Goyal and Joshi (2003) who have studied networks of collaboration between oligopolistic firms where a collaboration link between two firms involves a fixed cost and leads to an exogenously specified reduction in marginal production cost. Recently, Caulier, Mauleon, Sempere-Monerris and Vannetelbosch (2013) have introduced the framework of coalitional networks that can be applied to improve the predictions of existing economic models studying separately the formation of R\&D collaboration networks and of research joint ventures.

\section{Acknowledgments}

Vincent Vannetelbosch and Ana Mauleon are, respectively, Senior Research Associate and Research Associate of the National Fund for Scientific Research (FNRS). Financial support from the Spanish Ministry of Economy and Competition under the project ECO2012-35820, support from Generalitat Valenciana and FEDER under the projects ECO2010-20584 and PROMETEO/2009/068 are gratefully acknowledged.

\section{References}

[1] BELLEFLAMME, P. (2000) Stable coalition structures with open membership and asymmetric firms, Games and Economic Behavior 30, 1-21.

\footnotetext{
${ }^{11}$ Brooks, Landeo and Spier (2010) have provided theoretical and experimental explanations for why Texas Shootouts are included in business agreements.
} 
[2] BLOCH, F. (1995) Endogenous structures of association in oligopolies, Rand Journal of Economics 26, 537-556.

[3] BLOCH, F. (1996) Sequential formation of coalitions in games with externalities and fixed payoff division, Games and Economic Behavior 14, 90-123.

[4] BROOKS, R.R.W., C.M. LANDEO, and K.E. SPIER (2010) Trigger happy or gun shy? Dissolving common-value partnerships with Texas shootouts, RAND Journal of Economics 41, 649-673.

[5] CAUliER, J.F., A. MAULEON, J.J. SEMPERE-MONERRIS, and V. VANNETELBOSCH (2013) Stable and efficient coalitional networks, forthcoming in Review of Economic Design.

[6] DREZE, J.H., and J. GREENBERG (1980) Hedonic coalitions: optimality and stability, Econometrica 48, 987-1003.

[7] ESPINOSA, M.P., and I. MACHO-STADLER (2003) Endogenous formation of competing partnerships with moral hazard, Games and Economic Behavior 44, 183-194.

[8] GOYAL, S., and S. JOSHI (2003) Networks of collaboration in oligopoly, Games and Economic Behavior 43, 57-85.

[9] GULATI, R., M. SYTCH, and P. MEHROTRA (2008) Breaking up is never easy: planning for exit in a strategic alliance, California Management Review 50, 147-163.

[10] HAGEDOORN, J. (2002) Inter-firm R\&D partnerships: an overview of major trends and patterns since 1960, Research Policy 31, 477-92.

[11] HART, S., and M. KURZ (1983) Endogenous formation of coalitions, Econometrica 51, 1047-1064.

[12] HERINGS, P.J.J., A. MAULEON, and V. VANNETELBOSCH (2010) Coalition formation among farsighted agents, Games 1, 286-298.

[13] KONISHI, H., and D. RAY (2003) Coalition formation as a dynamic process, Journal of Economic Theory 110, 1-41. 
[14] MINEHART, D., and Z. NEEMAN (1999) Termination and coordination in partnerships, Journal of Economics and Management Strategy 8, 191-221.

[15] RAY, D., and R. VOHRA (1997) Equilibrium binding agreements, Journal of Economic Theory 73, 30-78.

[16] RAY, D., and R. VOHRA (1999) A theory of endogenous coalition structures, Games and Economic Behavior 26, 286-336.

[17] SMITH, G. (2005) The exit structure of strategic alliances, University of Illinois Law Review, 303-317.

[18] YI, S.S. (1997) Stable coalition structures with externalities, Games and Economic Behavior 20, 201-237.

[19] YI, S.S., and H. SHIN (2000) Endogenous formation of research coalitions with spillovers, International Journal of Industrial Organization 18, 229-56. 


\section{Recent titles}

\section{CORE Discussion Papers}

2012/54 Thierry BRECHET and Susana PERALTA. Markets for tradable emission permits with fiscal competition.

2012/55 Sudipto BHATTACHARYA, Claude D'ASPREMONT, Sergei GURIEV, Debapriya SEN and Yair TAUMAN. Cooperation in R\&D: patenting, licensing and contracting.

2012/56 Guillaume WUNSCH, Michel MOUCHART and Federica RUSSO. Functions and mechanisms in structural-modelling explanations.

2012/57 Simone MORICONI, Pierre M. PICARD and Skerdilajda ZANAJ. Commodity taxation and regulatory competition.

2012/58 Yurii NESTEROV and Arkadi NEMIROVSKI. Finding the stationary states of Markov chains by iterative methods.

2012/59 Tanguy ISAAC and Paolo PIACQUADIO. Equity and efficiency in an overlapping generation model.

2012/60 Luc BAUWENS, Giuseppe STORTI and Francesco VIOLANTE. Dynamic conditional correlation models for realized covariance matrices.

2012/61 Mikhail ESKAKOV and Alexey ISKAKOV. Equilibrium in secure strategies.

2012/62 Francis BLOCH and Axel GAUTIER. Strategic bypass deterrence.

2012/63 Olivier DURAND-LASSERVE, Axel PIERRU and Yves SMEERS. Sensitivity of policy simulation to benchmark scenarios in CGE models: illustration with carbon leakage.

2013/1 Pierre PESTIEAU and Maria RACIONERO. Harsh occupations, health status and social security.

2013/2 Thierry BRECHET and Henry TULKENS. Climate policies: a burden or a gain?

2013/3 Per J. AGRELL, Mehdi FARSI, Massimo FILIPPINI and Martin KOLLER. Unobserved heterogeneous effects in the cost efficiency analysis of electricity distribution systems.

2013/4 Adel HATAMI-MARBINI, Per J. AGRELL and Nazila AGHAYI. Imprecise data envelopment analysis for the two-stage process.

2013/5 Farhad HOSSEINZADEH LOTFI, Adel HATAMI-MARBINI, Per J. AGRELL, Kobra GHOLAMI and Zahra GHELEJ BEIGI. Centralized resource reduction and target setting under DEA control.

2013/6 Per J. AGRELL and Peter BOGETOFT. A three-stage supply chain investment model under asymmetric information.

2013/7 Per J. AGRELL and Pooria NIKNAZAR. Robustness, outliers and Mavericks in network regulation.

2013/8 Per J. AGRELL and Peter BOGETOFT. Benchmarking and regulation.

2013/9 Jacques H. DREZE. When Borch's Theorem does not apply: some key implications of market incompleteness, with policy relevance today.

2013/10 Jacques H. DREZE. Existence and multiplicity of temporary equilibria under nominal price rigidities.

2013/11 Jean HINDRIKS, Susana PERALTA and Shlomo WEBER. Local taxation of global corporation: a simple solution.

2013/12 Pierre DEHEZ and Sophie POUKENS. The Shapley value as a guide to FRAND licensing agreements.

2013/13 Jacques H. DREZE and Alain DURRE. Fiscal integration and growth stimulation in Europe.

2013/14 Luc BAUWENS and Edoardo OTRANTO. Modeling the dependence of conditional correlations on volatility.

2013/15 Jens L. HOUGAARD, Juan D. MORENO-TERNERO and Lars P. OSTERDAL. Assigning agents to a line.

2013/16 Olivier DEVOLDER, François GLINEUR and Yu. NESTEROV. First-order methods with inexact oracle: the strongly convex case.

2013/17 Olivier DEVOLDER, François GLINEUR and Yu. NESTEROV. Intermediate gradient methods for smooth convex problems with inexact oracle. 


\section{Recent titles}

\section{CORE Discussion Papers - continued}

2013/18 Diane PIERRET. The systemic risk of energy markets.

2013/19 Pascal MOSSAY and Pierre M. PICARD. Spatial segregation and urban structure.

2013/20 Philippe DE DONDER and Marie-Louise LEROUX. Behavioral biases and long term care insurance: a political economy approach.

2013/21 Dominik DORSCH, Hubertus Th. JONGEN, Jan.-J. RÜCKMANN and Vladimir SHIKHMAN. On implicit functions in nonsmooth analysis.

2013/22 Christian M. HAFNER and Oliver LINTON. An almost closed form estimator for the EGARCH model.

2013/23 Johanna M. GOERTZ and François MANIQUET. Large elections with multiple alternatives: a Condorcet Jury Theorem and inefficient equilibria.

2013/24 Axel GAUTIER and Jean-Christophe POUDOU. Reforming the postal universal service.

2013/25 Fabian Y.R.P. BOCART and Christian M. HAFNER. Fair re-valuation of wine as an investment.

2013/26 Yu. NESTEROV. Universal gradient methods for convex optimization problems.

2013/27 Gérard CORNUEJOLS, Laurence WOLSEY and Sercan YILDIZ. Sufficiency of cut-generating functions.

2013/28 Manuel FORSTER, Michel GRABISCH and Agnieszka RUSINOWSKA. Anonymous social influence.

2013/29 Kent WANG, Shin-Huei WANG and Zheyao PAN. Can federal reserve policy deviation explain response patterns of financial markets over time?

2013/30 Nguyen Thang DAO and Julio DAVILA. Can geography lock a society in stagnation?

2013/31 Ana MAULEON, Jose SEMPERE-MONERRIS and Vincent VANNETELBOSCH. Contractually stable alliances.

\section{Books}

G. DURANTON, Ph. MARTIN, Th. MAYER and F. MAYNERIS (2010), The economics of clusters Lessons from the French experience. Oxford University Press.

J. HINDRIKS and I. VAN DE CLOOT (2011), Notre pension en heritage. Itinera Institute.

M. FLEURBAEY and F. MANIQUET (2011), A theory of fairness and social welfare. Cambridge University Press.

V. GINSBURGH and S. WEBER (2011), How many languages make sense? The economics of linguistic diversity. Princeton University Press.

I. THOMAS, D. VANNESTE and X. QUERRIAU (2011), Atlas de Belgique - Tome 4 Habitat. Academia Press.

W. GAERTNER and E. SCHOKKAERT (2012), Empirical social choice. Cambridge University Press.

L. BAUWENS, Ch. HAFNER and S. LAURENT (2012), Handbook of volatility models and their applications. Wiley.

J-C. PRAGER and J. THISSE (2012), Economic geography and the unequal development of regions. Routledge.

M. FLEURBAEY and F. MANIQUET (2012), Equality of opportunity: the economics of responsibility. World Scientific.

J. HINDRIKS (2012), Gestion publique. De Boeck.

\section{CORE Lecture Series}

R. AMIR (2002), Supermodularity and complementarity in economics.

R. WEISMANTEL (2006), Lectures on mixed nonlinear programming.

A. SHAPIRO (2010), Stochastic programming: modeling and theory. 